\section{Efficient, stunning restorative treatment}

Common reasons for patients to switch practice include the promise of quicker and cheaper treatment.

But practitioners who use COLTENE's new BRILLIANT

COMPONEER can deliver efficient, stunning restorative treatment that is also cost effective.

BRILLIANT COMPONEER is a composite enamel translucent veneer that offers high gloss retention, polishability and stability. It can be used for minimally-invasive restorations that can be carried out chair-side and for a range of indications. Often, work can be carried out in one session.

Results with BRILLIANT COMPONEER are beautiful and stable. Contact the team today to find out why COLTENE is the preferred option for upgraded restorative dentistry.

To find out more visit www.coltene.com, email info.uk@coltene. com or call 01444235486.

\section{A recipe for implantology success}

Results are everything in implantology. To optimise your chances of treatment success, you need a system that encompasses all the relevant components - you need the Z1.

The result of 15 years of research, the $\mathrm{Z} 1$ offers biocompatibility, mechanical resistance, primary stability and longevity, with an average success rate of $98.6 \%$.

Plus, because it's universal and suits all types of prosthetic restorations (including traditional or CAD/CAM manufactured solutions), you don't need to worry about changing between systems - enabling you to dedicate your time to more important matters at hand.

For more information on the Z1 implant, visit tbr.dental, emailsupport@denkauk.com or call 08007076212.

\title{
First-class dental implant training
}

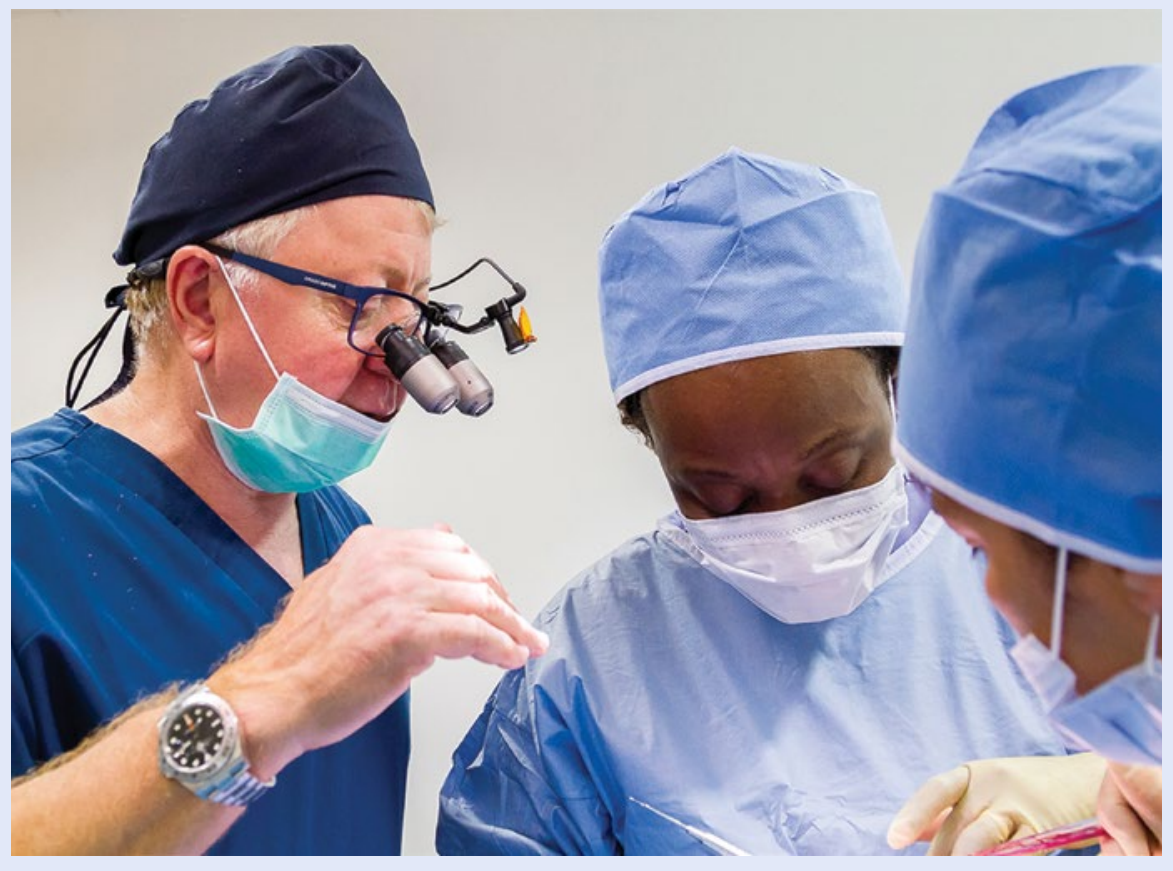

Ucer Education is a dedicated provider of first-class training and education within the field of dental implantology, catering to different needs and experience levels.

Led by renowned Specialist Oral Surgeon Professor Cemal Ucer, the PG Cert in Implant Dentistry provides a solid foundation in the field. The 12-month multi-system course provides a formal (EduQual level 7) award and includes both theoretical and practical sessions for comprehensive skill development.

For more experienced clinicians, there is a three-day intensive Sinus and Bone Grafting course with hands-on cadaver surgery.

Advance your dental implantology with first-training from Ucer Education.

For more information on the implant training available from Ucer Education, visit www.ucer.education or call 01612371842.

\section{Is your autoclave up to the task?}

Your autoclave is an essential part of your everyday workflows. But is your current model up to the task?

The Little Sister SES 2020N autoclave from Eschmann has a number of features that ensure your staff don't feel the strain even when days get busy. The 17-litre capacity can hold five full-sized instrument trays, meaning that staff won't have to use the autoclave so often during the day and can concentrate on providing more attentive patient care.

Furthermore, with rapid cycles and active drying, instruments are ready to be used much faster!

Introduce a new era of efficiency into your practice by contacting Eschmann for more information today.

For more information on the highly effective and affordable range of decontamination equipment and products from Eschmann, visit www.eschmann. co.uk or call 01903875787 .

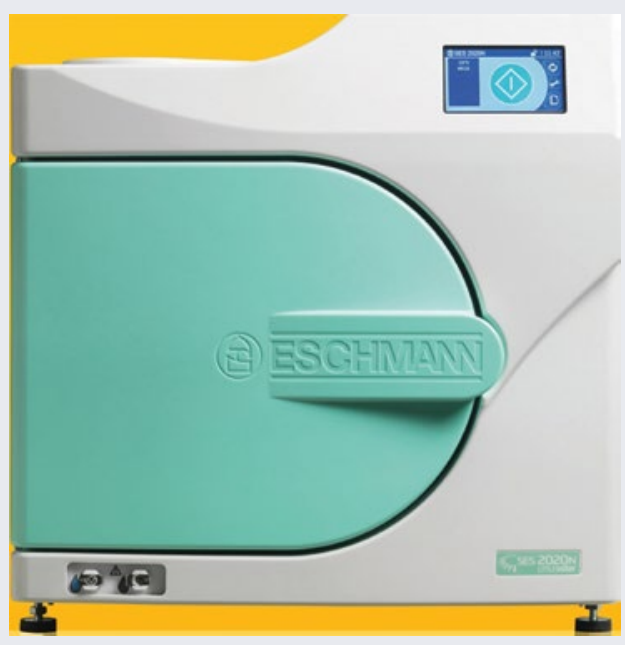

